\title{
Gender in Task Difficulty: Does It Make Difference in Macro-genres?
}

\author{
Yadollah Hosseini Asgarabadi
}

\author{
PhD Candidate in TEFL, Tehran Payame Noor University, PhD Center \\ Email: y_asgarabadi@yahoo.com
}

\section{Doi:10.5901/mjss.2016.v7n3s1p96}

\begin{abstract}
This study aimed to examine the role of the learners' gender in task difficulty in the four major types of macro-genres: the descriptive, narrative, argumentative, and expository. The design included the administration of short reading tests with comparable length and readability indices based on the four macro-genres (i.e., descriptive, narrative, argumentative, and expository) followed by task difficulty questionnaires. The macro-genre-based reading tests along with the task difficulty questionnaires were administered to 50 (male $=21$, female $=29$ ) EFL students in the University of Lorestan, Iran. Task difficulty questionnaires explored the learners' perceptions of task difficulty components (i.e., code complexity, cognitive complexity, and communicative stress). The results revealed that there were no statistically significant differences between males and females in the task difficulty of the four macro-genres. The findings hold implications for the use of macro-genres for male and female learners in task-oriented programs, genre-based teaching materials, teacher training, and testing.
\end{abstract}

Keywords: Gender, task difficulty, macro-genres, reading

\section{Introduction}

The learner's gender is a factor that is supposed to affect his/her L2 performance considerably. The role of the language learner's gender in his/her performance in different aspects of an L2 has already been explored. With regard to the role of gender in the learners' reading performance, for example, many research studies (e.g., Askov \& Fischbach, 1973; Coles \& Hall, 2002; Hall \& Coles, 1999; Kush \& Watkins, 1996; McKenna et al., 1995; Sainsbury \& Schagen, 2004; Smith, 1990) have been carried out. Some studies (e.g., Mullis, Martin, Kennedy, \& Foy, 2007) have indicated that females outscored the males in their reading comprehension. These findings attributed this superiority of females over males in the reading comprehension to the females having more positive attitudes to the reading task and more perseverance in keeping up with the reading ambiguities. Other studies (e.g., Ahmadi \& Mansoordehghan, 2012; Sotoudenamah \& Asadian, 2011; Bugel \& Buunk, 1996; Samadi \& Maghsoudi, 2013), in contrast, reported that male learners were better in the reading compression than the female ones. Hosseini, Rouhi, and Jafarigohar (2015) and Rouhi, Jafarigohar, Alavi, and Hosseini (2015), however, showed that there were no significant difference observed between males and females in their reading comprehension in the four major types of macro-genres (i.e., the descriptive, narrative, argumentative, and expository). The performance of males and females in the reading comprehension in the four types of macro-genres (i.e., descriptive, narrative, argumentative, and expository) is supposed to be an issue of interest in language teaching which may shed some light on the gender-related performance of the L2 learners and practitioners. Also of interest to L2 instructors and teachers may be the role of language learners' gender in their perceptions of a certain macro-genre level of task difficulty, a point which, in turn, may affect the learners' language performance like reading comprehension in macro-genre-based texts.

\section{Literature Review}

\subsection{Task Difficulty}

A central issue in task-based language teaching involves the impact of task difficulty on L2 learners' performance in various aspects of language learning and teaching, especially in the reading skill. Many of the previous empirical studies (e.g., Foster \& Skehan, 1999; Gilabert, 2007; Ishikawa, 2006; Kim, 2009; Robinson, 1995, 2001, 2007; Skehan \& Foster, 1999) have examined the effects of task difficulty on L2 learners' oral task performance but relatively few studies (e.g., Ishikawa, 2006; Kuiken \& Vedder, 2008) have investigated the role of task difficulty in reading performance of the learners. 
The four major approaches which are employed and referred to in task-based research are the psychological, sociocultural, structural, and cognitive (see Kuiken \& Vedder, 2008). Among these approaches, Robinson (2001, 2003, 2005) and Skehan and Foster $(1999,2001)$ used the cognitive approach in which the focus is on the cognitive processes used by learners while performing a certain language task. Robinson $(2001,2003,2005)$ and Skehan and Foster (1999, 2001) investigated how task complexity (a concept closely related to task difficulty) influenced the L2 learners' performance.

In Robinson's (2001) triadic componential framework, the task components are task complexity, task conditions, and task difficulty. The underlying foundation for this framework is based on the cognition hypothesis. According to Robinson and Gilabert (2007), the main pedagogic claim of the cognition hypothesis is that pedagogic tasks should be designed and sequenced on the basis of increases in their cognitive complexity and cognitive processing load. Robinson and Gilabert (2007) stated that the information about the effect of task complexity on language performance could be used to guide decision-making about sequencing tasks in syllabus design used for materials in the macro-genre text types for the language learners.

Task conditions include participation and participant factors. Task conditions refer to all external variables and influential factors which are supposed to exert their effect on the language learners' performance. In other words, task condition is concerned with the logistic factors of teaching and learning in the language task.

Task complexity in Robinson's (2001) triadic componential framework is defined as the result of attentional, memory, reasoning, and other information processing demands imposed by the structure of the task on the language learner. It is a cognitive process in nature which can be manipulated by teachers and syllabus designers before task performance (see Ishikawa, 2006). Robinson (2005) believed that information about the effect of task complexity on language performance was helpful in designing tasks from simple to complex to gradually approximate real world task demands.

In Robinson's (2001) triadic componential framework, task difficulty refers to the learners' perceptions of the difficulty of a certain language task. Some factors such as proficiency and anxiety affecting learners' perceptions of difficulty of macro-genre-based reading texts are, however, difficult to identify before task performance. Therefore, they cannot be used as a basis for decision-making in sequencing tasks.

Skehan (1998) defined task difficulty as a concept consisting of cognitive factors that could be manipulated during task design to obtain the desired elicitation behavior of language learner. According to Skehan $(1996,1998)$, three areas are important in determining task difficulty of a certain language task: code complexity, cognitive complexity, and communicative stress. Code complexity of a task includes linguistic as well as lexical complexity. Both linguistic complexity or variety and vocabulary load/variety play important roles in code complexity. Code complexity, thus, deals with the lexical items and the grammatical structures used in the texts. Idiomatic structure is, for instance, one of the factors affecting code complexity which, in turn, may affect the reading performance of the learners in macro-genres. Martinez and Murphy (2011) found that the use of idiomatic structures in reading texts can be detrimental to learners' reading performance. Cognitive complexity of a task, in contrast, refers to the cognitive processing and cognitive familiarity. It involves processing factors such as information type and organizational structures as well as the familiarity of the learners with the topic of discourse and genre type (Skehan, 1998). A factor which is supposed to be closely related to cognitive complexity and to affect the learners' performance in reading rhetorical and genre text types is schemata which are categorized into linguistic, formal, and content (Xiao-hui, Jun, \& Wei-hui, 2007). Communicative stress of a task (as the third component of task difficulty) is, however, concerned with time pressure, modality, scale, stakes, and control. This component of task difficulty, thus, refers to the logistics as well as resources of task performance including the nature of the prompt provided and the number of participants in the process of task performance. Research studies (e.g., Foster \& Skehan, 1996; Skehan \& Foster, 1997, 1999) have shown that more complex tasks (in terms of time pressure and high degrees of control) direct learners' attention to context and divert their attention away from the form of the language. Simple tasks, in contrast, generate more fluent and more accurate language, as opposed to more complex tasks which generate more complex language at the expense of accuracy and fluency.

\subsection{Macro-genres}

Four types of macro-genres (i.e., narrative, descriptive, argumentative, and expository) were employed in this study. The first macro-genre used was the narrative macro-genre which is a well-established text type in language teaching literature and is also frequently employed for teaching and testing purposes by L2 practitioners. Such a text type usually involves the creation of a story in response to some kind of stimulus. This macro-genre seems ideal as far as the manifestation of 
creativity and narration power among the L2 learners is concerned (Albert \& Kormos, 2004). The narrative text type is thought to be associated with the improvement of the learners' intellectual powers of imagination and creativity which, in turn, can pave the way for other functions of the language like regulatory and imaginative to develop. Working with the narrative macro-genre is supposed to help language practitioners see clear sequences separate from all other mental functions (Best, Floyd, \& McNamara, 2008). Psychologically viewed, using and developing the narration ability of the language learners is likely to lead to the establishment of mental disciplines and logical order in discourse.

Another type of macro-genre employed in teaching English to L2 learners is the descriptive macro-genre the purpose of which is to recreate, invent, or visually present a person, place, event, or action so that the reader can picture that which is being described. Descriptive macro-genre can also be found in other rhetorical modes of language including journal writing and poetry (Diakidoy, Stylianou, Karefillidou, \& Papageorgiou, 2004). The language used in the description has ostensible patterns. In producing linear descriptions of figures, for example, learners tend to facilitate the task by sequencing the content in one of a small number of ways, leading to specific patterns in the language (Al-Sohbani, 2014; Bax, 2006). The nature of objects physically related within a room whose layout is to be described can affect the order in which nouns are combined within prepositional phrases, and this, in turn, can affect the choice of preposition (Hyland, 2008). Psychologically viewed, the descriptive macro-genre is thought to lead to the language learners' improvement in logical reasoning and categorizing items in clear patters.

Argumentative macro-genre is a type of discourse genre in which efforts of the individuals to build support for their own position, at the same time that they are undermining support for an opponent's position, result in the continual negotiation of referential, social, and expressive meanings. It is not only viewed as a competitive process, but also as a cooperative act, which is an important characteristic of the discourse produced by participants (Nemeth \& Kormoth, 2001).

Expository macro-genre is thought to convey, describe, or explain non-fictional information (Yopp \& Yopp, 2006). Such text types include structural organization of the concepts and propositions which differentiate them from the rest of texts. The aim of this macro-genre text type is to present people the facts, ideas, and to explain the historical events and social phenomena, to clarify the political opinions, and to test findings and evidence in different domains. It is also intended to explain all that is in need of explanation and clarification. The focus of the discourse in the expository macrogenre is generally the central idea surrounded by supporting details (Samuelstuen \& Braten, 2005). Learners' reasoning powers and explanation abilities may be strengthened through practicing the expository macro-genre tasks (Barbara \& Samuels, 1983; Samuelstuen \& Braten, 2005). Psychologically viewed, the expository macro-genre may spur the learners' motivation to keep on reading such texts. This, in turn, can result in improving the learners' proficiency in the reading skill, in general.

As said earlier, the role of the language learners' gender in many different domains of an L2 has already been explored. The role of the learner's gender in task difficulty of macro-genres, however, has not been studied, as yet. This felt gap in the literature of teaching English is the driving motive behind the current study for which the following research question along with the research hypothesis is addressed: genres?

Research Question: Does the learners' gender make difference in their perceptions of task difficulty in macro-

Research hypothesis: Learners' gender does not make difference in their perceptions of task difficulty in macrogenres with the probability level set at 0.05 .

\section{Method}

\subsection{Participants}

A total of 50 participants (21 male and 29 female) majoring in EFL in the English department of university of Lorestan were randomly selected (systematic randomization). The participants were second year students having at least seven years of experience in English in academic centers. Their ages ranged from 18 to 25 with age mean of 19.6. The participants were at the intermediate level based on the scores they got from a proficiency test (a standard test administered to determine participants' proficiency level in English, $r=.87$ ). All the participants were informed of the research and its stages and they expressed that they would attend in the study voluntarily. The participants reported having no special experience in attending formal or informal preparatory classes for genre-based reading texts. The participants also reported that they knew the meaning of task and task-based language teaching. They reported Lacki and Lori as their first languages and Persian as their second language. Subjective and in-class survey indicated that the participants came from families with approximately similar socioeconomic status. 


\subsection{Design}

This study employed a comparative design in which male and female groups were compared in their task difficulty perceptions of the four main types of macro-genres through running independent $t$-test. In each comparison, the two groups of males and females are compared in one macro-genre (See the following diagram).

\begin{tabular}{|l|c|c|c|c|}
\hline \multirow{2}{*}{ Gender } & \multicolumn{4}{|c|}{ Macro-genres } \\
\cline { 2 - 5 } & Descriptive & Narrative & Argumentative & Expository \\
\hline Females & t-test 1 & t-test 2 & $t$-test 3 & $t$-test 4 \\
\hline Males & test &
\end{tabular}

\subsection{Materials}

In order to explore the learners' perceptions of task difficulty in the four types of macro-genres, Skehan's (1998) checklist, developed based on his triadic framework of task difficulty, was used. This checklist measured the learners' perceptions of task difficulty in code complexity, cognitive complexity, and communicative stress domains, as three components comprising task difficulty. Moreover, for reading comprehension, three short reading texts with the same length and readability indices for each of the four macro-genres were used. To prepare comparable reading texts in the four macrogenre text types, Coh-Metrix Common Core formula as the reading Text Ease and Readability Assessor (TERA), developed by Crossley and Greenfield (2008), were used. From the selected reading texts for the four types of macrogenres, appropriate reading tests (with reliability indices of $.77, .83, .85, .75$ for the descriptive, narrative, argumentative, and expository macro-genres, respectively) were also constructed. Moreover, in order to determine the proficiency level of the participants, a standard proficiency reading pre-test taken from Barron's How to Prepare for the TOEFL Test: Test of English as a Foreign Language (Sharpe, 2004) with the reliability index of .76 was used.

\subsection{Procedures}

In the process of selecting the intended reading texts for the research, some passages for the four macro-genres were selected and their readability indices were computed through running the Coh-Metrix formula (Crossley \& Greenfield, 2008) (TERA: Text Ease and Readability Assessor). Coh-Metrix analysis provided the readability indices for the selected reading texts. Furthermore, in the pilot study for the selected reading passages administered to the pilot group (20 EFL majors), all the items meeting the item facility value between .25 and .75 and item discriminatory value more than .30 (see Baker, 1989) were selected to be used in the testing stage.

Then, texts falling in the intermediate range in each macro-genre [based on indices taken from applying the CohMetrix Common Core: Text Ease and Readability Assessor (Crossley \& Greenfield, 2008)] were selected and reading tests were, accordingly, constructed and given to $80 \mathrm{EFL}$ students. Based on Cambridge Guide to TEFL Exams and Levels, the participants whose scores fell between $50 \%$ and $70 \%$ of the total score (taken from TOEFL proficiency Test) were judged as being in the intermediate level. Fifty participants with scores in the intermediate level range were, finally, selected as the research sample.

As said earlier, twelve short reading texts with the same readability indices and length were prepared for administration. This was followed by constructing appropriate reading tests for the macro-genres. In the first week, the descriptive macro-genre reading tests followed by distributing task difficulty questionnaires were administered to the participants. All the steps were taken just for one type of macro-genre text type in each session. With three days interval, the same steps were followed for the rest of other three macro-genres (i.e., the narrative, argumentative, and expository). Moreover, to obtain more valid and reliable results, task difficulty questionnaire was translated into Persian. Correspondence between the original and Persian equivalents of each item in the questionnaire was judged by three experienced English teachers. The translation output was, finally, judged and approved of by an expert in the field. Male and female participants' options in the task difficulty questionnaires were, then, compiled for running statistical analysis. The data were, finally, fed into SPSS, version 20. The significance level was set at $p<0.05$.

\section{Results}

To provide a clear depiction of the two groups of males' and females' perceptions in task difficulty in the four macrogenres (i.e., the descriptive, narrative, argumentative, and expository) used in the current study, the group statistics (e.g., 
mean, standard deviation) are presented followed by the results of comparisons run by independent t-test in the following tables and figures.

As indicated in Table 2, there was no statistically significant difference observed between males and females in their task difficulty perceptions in the descriptive macro-genre, $t=-1.005, p=.320>0.05$, eta squared $=0.33$. Although no significant difference was observed between the compared groups in the task difficulty of the descriptive macro-genre, the group statistics showed that there was a small difference observed in the means and standard deviations of the groups compared (females: $M=43.58, S D=6.77$; males: $M=45.57, S D=7.06$ ) (see Table 1).

Table 1: Group Statistics

\begin{tabular}{cccccc}
\hline & sex & N & Mean & Std. Deviation & Std. Error Mean \\
\hline \multirow{2}{*}{ Descriptive TD } & female & 29 & 43.58 & 6.77 & 1.25 \\
& male & 21 & 45.57 & 7.06 & 1.54 \\
\hline
\end{tabular}

Table 2: Independent $t$-Test for Males and Females Task Difficulty in Descriptive Macro-genre

\begin{tabular}{|c|c|c|c|c|c|c|c|c|c|}
\hline \multirow{2}{*}{\multicolumn{2}{|c|}{ LTEV }} & \multicolumn{8}{|c|}{ t-test for Equality of Means } \\
\hline & & $\mathrm{F}$ & Sig. & $\mathrm{t}$ & df & Sig (two-tailed) & Mean Difference & Std. & $\begin{array}{c}95 \% \mathrm{Cl} \\
\text { Lower Upper }\end{array}$ \\
\hline Descriptive TD & $\begin{array}{l}\text { EVA } \\
\text { EVNA }\end{array}$ & .222 & 639 & $\begin{array}{c}-1.005 \\
.998 \\
\end{array}$ & $\begin{array}{c}48 \\
42.16 \\
\end{array}$ & $\begin{array}{l}.320 \\
.324 \\
\end{array}$ & $\begin{array}{l}-1.98 \\
-1.98\end{array}$ & $\begin{array}{l}1.97 \\
1.98 \\
\end{array}$ & $\begin{array}{rr}-5.95 & 1.98 \\
-5.99 & 2.02 \\
\end{array}$ \\
\hline
\end{tabular}

Note: EVA = Equal Variances Assumed; EVNA = Equal Variances Not Assumed; $\mathrm{Cl}=$ Confidence Interval LTEV = Levene's Test for Equality of Variances

Results of males' and females' perceptions in task difficulty in the descriptive macro-genre are also presented in Figure 1.

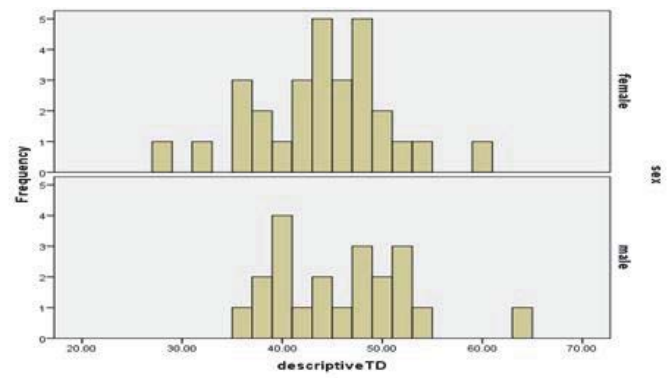

Figure 1: Males' and Females' Task Difficulty in Descriptive Macro-genre

As indicated in Table 3, in the narrative macro-genre, the two groups had small differences in group statistics (females: $M=47.24, S D=8.48$; males: $M=48.71, S D=5.88$ ).

Table 3: Group Statistics

\begin{tabular}{lccccc}
\hline & sex & N & Mean & Std. Deviation & Std. Error Mean \\
\hline \multirow{2}{*}{ Narrative TD } & female & 29 & 47.24 & 8.48 & 1.57 \\
& male & 21 & 48.71 & 5.88 & 1.28 \\
\hline
\end{tabular}

Results of $t$-test comparison made between the two groups of male and female learners showed that there was no significant difference between the groups compared in the task difficulty in the narrative macro-genre, $t=-.684, p=.497$ $>0.05$, eta squared $=.186$ (Table 4). 
Table 4: Independent t-Test for Males and Females Task Difficulty in the Narrative Macro-genre

\begin{tabular}{|c|c|c|c|c|c|c|c|c|c|}
\hline \multirow{2}{*}{\multicolumn{2}{|c|}{ LTEV }} & \multicolumn{8}{|c|}{ t-test for Equality of Means } \\
\hline & & $\mathrm{F}$ & Sig. & $\mathrm{t}$ & df & Sig (two-tailed) & Mean Difference & Std. & $\begin{array}{c}95 \% \mathrm{Cl} \\
\text { Lower Upper }\end{array}$ \\
\hline Narrative TD & $\begin{array}{l}\text { EVA } \\
\text { EVNA }\end{array}$ & 1.9 & 172 & $\begin{array}{l}-.684 \\
-.725\end{array}$ & $\begin{array}{c}48 \\
47.93\end{array}$ & $\begin{array}{l}.497 \\
.472\end{array}$ & $\begin{array}{l}-1.47 \\
-1.47\end{array}$ & $\begin{array}{l}2.15 \\
2.03\end{array}$ & $\begin{array}{ll}-5.80 & 2.85 \\
-5.56 & 2.61\end{array}$ \\
\hline
\end{tabular}

Note: EVA = Equal Variances assumed; EVNA = Equal Variances Not Assumed; $\mathrm{Cl}=$ Confidence Interval; LTEV = Levene's Test for Equality of Variances

Furthermore, results of male and female groups' task difficulty in the narrative macro-genre are indicated in Figure 2.

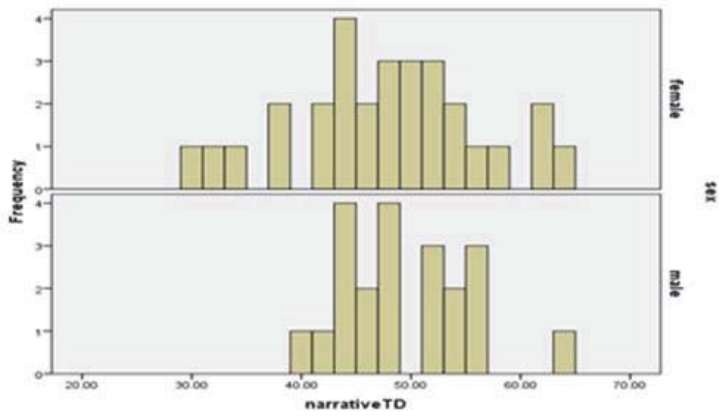

Figure 2: Males' and Females' Task Difficulty in the Narrative Macro-genre

In the argumentative macro-genre, group statistics showed that the results of males' perceptions of task difficulty were bigger than those in females (females: $M=45.62, S D=11.26$; males: $M=50.00, S D=6.00$ ) (see Table 5 and Figure 3).

Table 5: Group Statistics

\begin{tabular}{cccccc}
\hline & sex & N & Mean & Std. Deviation & Std. Error Mean \\
\hline \multirow{2}{*}{ Argumentative TD } & female & 29 & 45.62 & 11.26 & 2.09 \\
& male & 21 & 50.00 & 6.00 & 1.30 \\
\hline
\end{tabular}

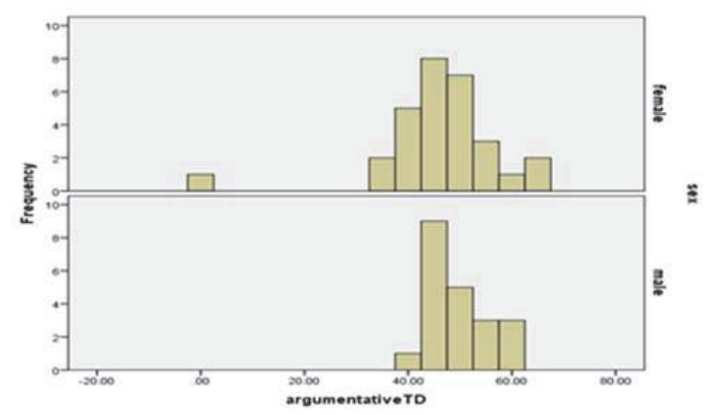

Figure 3: Males' and Females Task Difficulty in the Argumentative Macro-genre

As indicated in Table 6, there was no significant difference between the groups compared in task difficulty in the argumentative macro-genre, $t=1.62, p=.112>0.05$, eta squared $=0.051$. 
Table 6: Independent $t$-Test for Males and Females Task Difficulty in the Argumentative Macro-genre

\begin{tabular}{|c|c|c|c|c|c|c|c|c|c|}
\hline \multirow{3}{*}{ LTEV } & \multirow{3}{*}{$\mathrm{F}$} & \multirow{3}{*}{ Sig. } & \multicolumn{7}{|c|}{ t-test for Equality of Means } \\
\hline & & & $t$ & $d f$ & Sig (twontailed) & nifference & Std & $95 \%$ & \\
\hline & & & $l$ & al & sig (two-lallea) & Ivean Dinerence & sta. & Lower & Upper \\
\hline \multirow{2}{*}{ Argu-mentative TD } & EVA & & 1.62 & 48 & .112 & -4.37 & 2.70 & -9.81 & 1.05 \\
\hline & EVNA & 8 & -1.77 & 44.64 & .083 & -4.37 & 2.46 & -9.35 & .592 \\
\hline
\end{tabular}

Note: EVA = Equal Variances assumed; EVNA = Equal Variances Not Assumed; Cl = Confidence Interval; LTEV = Levene's

Test for Equality of Variances

In the expository macro-genre, the group statistics for males and females showed that males got bigger scores than females (females: $M=48.27, S D=7.09$; males: $M=52.09, S D=6.98$ ) (see Table 7 and Figure 4).

Table 7: Group Statistics

\begin{tabular}{cccccc}
\hline & sex & N & Mean & Std. Deviation & Std. Error Mean \\
\hline \multirow{2}{*}{ Expository TD } & female & 29 & 48.27 & 7.09 & 1.31 \\
& male & 21 & 52.09 & 6.98 & 1.52 \\
\hline
\end{tabular}

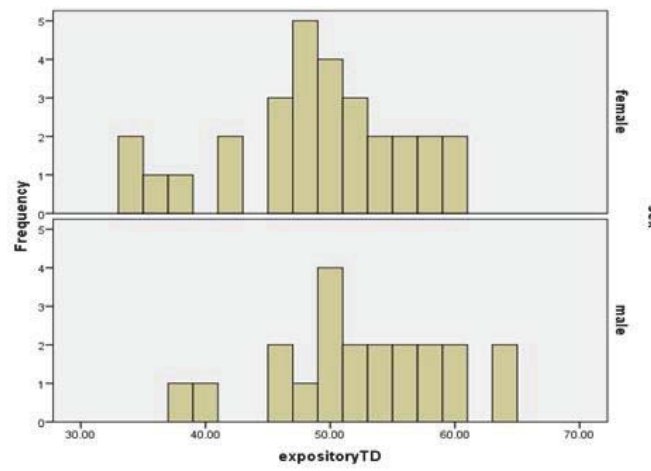

Figure 4: Males' and Females' Task Difficulty in Expository Macro-genre

Results of $t$-test comparison made between the male and female groups showed that there was no significant difference observed between the groups in the participants' perception of task difficulty in the expository macro-genre, $t=-1.89, p=$ $.065>0.05$, eta squared $=0.64$.

Table 8: Independent t-Test for Males and Females Task Difficulty in Expository Macro-genre

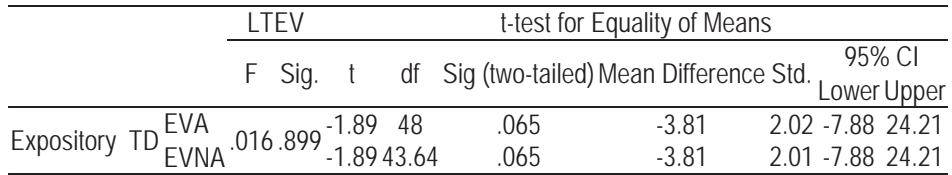

Note: EVA = Equal Variances assumed; EVNA = Equal Variances Not Assumed; LTEV = Levene's Test for Equality of Variances

The general finding was that in all the comparisons done between the female and male groups with regard to their perceptions of task difficulty in the four main types of macro-genres employed in the current study no significant difference was observed, showing that the groups compared belonged to the same population, although there were found differences in the group statistics (e.g., mean, standard deviation) for females and males. 


\section{Discussion and Conclusions}

This study has tried to investigate the role of gender in task difficulty of macro-genres (i.e., descriptive, narrative, argumentative, and expository). Results of $t$-test comparisons revealed that there were no significant differences observed between the male and the female participants with regard to their perceptions of task difficulty in the descriptive, narrative, argumentative, and expository macro-genre-based text types.

In ELT literature, two psychological hypotheses for the role of gender on learners' performances have been frequently presented and referred to: the similarities and the differences hypotheses. The findings of the current study are more compatible with the gender similarities hypothesis proposed by Hyde (2005) than with gender differences hypothesis put forward by Buss (1989). The gender similarities hypothesis holds that males and females are alike on most (but not all) psychological variables including the learner's reading comprehension. Extensive evidence from metaanalyses of research studies on gender differences supports the gender similarities hypothesis (Hyde, 2005). A few notable exceptions are some motor behaviors (e.g., throwing distance) and some aspects of sexuality, which show large gender differences. It is time to consider the costs of overinflated claims of gender differences. Arguably, such claims cause harm in numerous realms, including females' opportunities in the workplace and their performances in educational contexts (Hyde, 2005).

Lack of significant difference between the male and female groups in task difficulty of macro-genre-based reading texts may also be accounted for by the sociocultural theory, based on the pioneering work of Vygotsky (1986), which places the social context at the heart of the learning and communication process. In the Vygotskian social interactionist constructivism, learners can profit from social interactions under guidance or in collaboration with more capable peers. This guidance or collaboration is called scaffolding (see Yu, 2004). Through utilizing cooperative learning activities such as pair or group work in language learning in a learner-centered setting, learners can gain support/scaffolding from their peers or teacher. Such a scaffolding condition might have been running in the students' casual classes (out of testing situations) in which both male and female groups took advantages from cooperating with each other in enhancing their reading ability in macro-genres and raising strategy-use consciousness in tackling such texts reading problems. Such out of academic program cooperation among male and female learners might have led them to improve their reading abilities in parallel; hence it might have affected their perceptions of task difficulty in the macro-genre-based texts.

The current finding might have been affected by common and background information and previous experiences of both genders, as well. The two groups of male and female learners might have employed similar reading techniques and strategies to overcome the encountered problems while reading the macro-genre-based texts. No significant differences observed between the groups involved may also be attributed to the selection of reading passages. The reading passages employed in the current study might not have been challenging enough for the differences between the groups to appear. Presenting the groups with more challenging reading texts probably lets the differences between the two groups in task difficulty perceptions show themselves. Moreover, participants in the current study came from similar language background (Lacki and Lori languages); this might have made the participants process the reading passages similarly. The other variable supposed to contribute to the lack of statistical significant difference between the male and female learners' reading comprehension as well as their perceptions of the texts task difficulty might be equal time spent on reading the passages. The amount of time required for the participants to read texts with comprehension was not the same (and, in fact, should not be) and this might have resulted in the suppression of the differences between the groups compared. Females are usually more motivated, both intrinsically and extrinsically, to read texts on various topics (Baker \& Wigfield, 1999; Marinak \& Gambrell, 2010; Pajares \& Valiante, 2001; Wigfield \& Guthrie, 1997). In EFL context and at the intermediate level, this motivation may have acted equally for both groups of participants which, in turn, did not let the differences in reading comprehension along with task difficulty perceptions between the two groups reach the statistical significance.

The results of the current study are consistent with previous ones. Meece and Miller (1999), Wigfield and Guthrie (1997), and Sotoudehnama and Asadian (2011), for example, reported no significant differences between male and female learners' reading comprehension. Durik et al. (2006) and Logan and Johnston (2009) also found no significant differences in the reading comprehension of the two groups.

The findings of the study are, however, in contradiction with the findings of some previous studies (e.g., Askov \& Fischbach, 1973; Coles \& Hall, 2002; Doolittle \& Welsch, 1989; Hall \& Coles, 1999; Kush \& Watkins, 1996; McKenna et al., 1995; Sainsbury \& Schagen, 2004; Smith, 1990). In these studies, females were reported to significantly outperform the males in the comprehension of the reading texts. Al-Shumaimeri (2006), Bügel and Buunk (1996), and Dörnyei (2005) showed that male students performed significantly better than the female students in their reading performance of a familiar and an unfamiliar text. Bügel and Buunk (1996) included a gender-neutral passage in their L2 study, and they 
found that males performed significantly better than the females on the gender-neutral text.

There are some limitations to this study. The sample selected for this study was from among EFL students. The performance of other non-English majors in reading the four types of macro-genre-based texts seems to be important, as well. Non-English learners in male and female groups may perform differently in reading the macro-genre-based passages and in perceiving the relevant task difficulty of the texts. Furthermore, participants of the current study were from intermediate level. The performance of male and female students in reading these macro-genres may be different at primary and advanced levels; the findings, thus, cannot be generalized to these contexts. It can be concluded from the findings of this study that the learners' gender makes no significant difference in their perceptions of task difficulty of the four major types of macro-genres. The findings of the current study hold implications for genre-based reading materials, teacher training, ESP courses, and testing.

\section{References}

Ahmadi, A. \& Mansoordehghan, S. (2012). Comprehending a non-text: A study of gender-based differences in EFL reading comprehension. Journal of Language Teaching and Research, 3(4), 761-770.

Albert, A., \& Kormos, J. (2004). Creativity and narrative task performance: An exploratory study. Language Learning, 54(2), 277-310.

Al-Shumaimeri, Y. (2006). The effects of content familiarity and language ability on reading comprehension performance of low-and highability Saudi tertiary students studying English as a foreign language. Educational Sciences and Islamic Studies, 18(2), 1-19.

Al-Sohbani, Y. A. (2014). A proposed framework for teaching reading integratively. Journal of Teaching and Teacher Education, 2(1), $67-76$.

Askov, E. N., \& Fischbach, T. J. (1973). An investigation of primary pupils' attitude towards reading. The Journal of Experimental Education, 41(3), 1-7.

Baker, D. (1989). Language testing: A critical survey and practical guide. London: Arnold Publications.

Baker, L., \& Wigfield, A. (1999). Dimensions of children's motivation for reading and their relations to reading activity and reading achievement. Reading Research Quarterly, 34(4), 452-477.

Barbara, M. T., \& Samuels, S. J. (1983). Children's use of text structure in the recall of expository material. American Educational Research Journal, 20(4), 517-528.

Bax, S. (2006). The role of genre in language syllabus design: The case of Bahrain. International Journal of Educational Development, $26,315-328$.

Best, R. M., Floyd, R. G., \& McNamara, D. S. (2008). Differential competencies contributing to children's comprehension of narrative and expository texts. Reading Psychology, 29, 137-164.

Bügel, K., \& Buunk, B. P. (1996). Sex differences in foreign language text comprehension: The role of interest and prior knowledge. Modern Language Journal, 80, 15-31.

Buss, D. V. (1989). Sex differences in human mate preferences: Evolutionary hypotheses tested in 37 cultures. Behavioral and Brain Sciences, 12, 1-49.

Coles, M., \& Hall, C. (2002). Gendered readings: Learning from children's reading choices. Journal of Research in Reading, 25(1), 96108.

Crossley, S., \& Greenfield, J. (2008). L1 readability: Assessing text readability using cognitively-based indices. TESOL Quarterly, 42(3), $475-493$.

Diakidoy, N. J., Stylianou, P., Karefillidou, C., \& Papageorgiou, P. (2004). The relationship between listening and reading comprehension of different types of texts at increasing grade levels. Reading Psychology, 26, 55-80.

Doolittle, A., \& Welch, C. (1989). Gender differences in performance on a college-level achievement test. lowa City, IA: American College Testing Program.

Dörnyei, Z. (2005). The psychology of the language learning: Individual differences in second language acquisition. London: Lawrence Erlbaum.

Durik, A. M., Vida, M., \& Eccles, J. S. (2006). Task values and ability beliefs as predictors of High school literacy choices: A developmental analysis. Journal of Educational Psychology, 98(2), 382-393.

Elder, C., Iwashita, N., \& McNamara, T. (2002). Estimating the difficulty of oral proficiency tasks: What does the test-taker have to offer? Language Testing, 19(4), 343-368.

Foster, P., \& Skehan, P. (1999). The influence of source of planning and focus of planning on task-based performance. Language Teaching Research, 3(3), 215-247.

Gilabert, R. (2007). Effects of manipulating task complexity on self-repairs during L2 oral production. International Review of Applied Linguistics, 45, 215-240.

Hall, C., \& Coles, M. (1999). Children's reading choices. London: Routledge.

Henning, G. (2012). Twenty common testing mistakes for EFL teachers to avoid. English Teaching Forum, 20(3), 33-38.

Hosseini A., Y., Rouhi, A., \& Jafarigohar, M. (2015). Learners' gender, reading comprehension, and reading strategies in descriptive and narrative macro-genres. Theory and Practice in Language Studies, 5(12), 2557-2564.

Hyde, J. S. (2005). The gender similarities hypothesis. American Psychological Association, 60(6), 581-592.

Ishikawa, T. (2006). The effects of task complexity and language proficiency on task-based language performance. The Journal of Asia 
TEFL, 3(4), 193-225.

Kuiken, F., \& Vedder, I. (2008). Cognitive task complexity and written output in Italian and French as foreign languages. Journal of Second Language Writing, 17, 48-60.

Kush, J. C., \& Watkins, M. W. (1996). Long-term stability of children's attitudes towards reading. The Journal of Educational Research, 89(5), 315-317.

Logan, S., \& Johnston, R. S. (2009). Gender differences in reading: Examining where these differences lie. Journal of Research in Reading, 32(2), 199-214.

Marinak, B. A., \& Gambrell, L. B. (2010). Reading motivation: Exploring the elementary gender gap. Literacy Research and Instruction, 49, 129-14.

Martinez, R., \& Murphy V. (2011). Effect of frequency and ideomaticity on second language reading comprehension. TESOL Quarterly, 45(2), 267-290.

McKenna, M. C., Kear, D. J., \& Ellsworth, R. A. (1995). Children's attitudes toward reading: A national survey. Reading Research Quarterly, 30(4), 934-956.

Meece, J. L., \& Miller, S. D. (1999). Changes in elementary school children's achievement goals for reading and writing: Results of a longitudinal and an intervention study. Scientific Studies of Reading, 3(3), 207-229.

Mullis, I. V. S., Martin, M. O., Kennedy, A. M., \& Foy, P. (2007). PIRLS 2006 international report: IEA's progress in international reading literacy study in primary schools in 40 countries. Boston College: Chestnut Hill.

Nemeth, N., \& Kormos, J. (2001). Pragmatic aspects of task-performance: The case of argumentation. Language Teaching Research, $5(3), 213-240$.

Pajares, F., \& Valiante, G. (2001). Gender differences in writing motivation and achievement of middle school students: A function of gender orientation? Contemporary Educational Psychology, 26, 366-381.

Robinson, P. (2001). Task complexity, task difficulty, and task production: Exploring interactions in a componential framework. Applied Linguistics, 22(1), 27-57.

Robinson, P. (2003). The cognition hypothesis, task design, and adult task-based language learning. Second Language Studies, 21(2), $45-105$.

Robinson, P. (2005). Cognitive complexity and task sequencing: Studies in a componential framework for second language task design. International Review of Applied Linguistics, 43, 1-32.

Robinson, P., \& Gilabert, R. (2007). Task complexity, the cognition hypothesis, second language learning, and performance. International Review of Applied Linguistics, 45(3), 161-176.

Rouhi, A., Jafarigohar, M., Alavi, M., \& Hosseini A., Y. (2015). Task difficulty of macro-genres and reading strategies, and reading comprehension. International Journal of Asian Social Sciences, 5(11), 656 -677.

Sainsbury, M., \& Schagen, I. (2004). Attitudes to reading at ages nine and eleven. Journal of Research in Reading, 27(4), 373-386.

Samadi, F., \& Maghsoudi, M. (2013). Bilingual versus monolingual learners' reading comprehension ability regarding their interest in reading comprehension topics. European Online Journal of Natural and Social Science, 2(2), 23-34.

Samuelstuen, M. S., \& Braten, I. (2005). Decoding, knowledge, and strategies in comprehension of expository text. Scandinavian Journal of Psychology, 46, 107-117.

Sharpe, P. J. (2004). How to prepare for the TOEFL test of English as a foreign language. New York: Barron's Publications.

Skehan, P. (1996). A framework for the implementation of task-based instruction. Applied Linguistics, 17(1), 38-62.

Skehan, P. (1998). A cognitive approach to language learning. Oxford: Oxford University Press.

Skehan, P., \& Foster, P. (1997). Task type and task processing conditions as influences on foreign language performance. Language Teaching Research, 4(3), 185-211.

Skehan, P., \& Foster, P. (1999). The influence of task structure and processing conditions on narrative retellings. Language Learning, $49(1), 93-120$.

Skehan, P., \& Foster, P. (2001). Cognition and tasks. In P. Robinson (Ed.), Cognition and second language instruction (pp.183-205). Cambridge: Cambridge University Press.

Smith, M. C. (1990). A longitudinal investigation of reading attitude development from childhood to adulthood. Journal of Educational Research, 83, 215-219.

Sotoudehnama, E., \& Asadian, M. (2011). The effect of gender-oriented content familiarity and test type on reading comprehension. The Journal of Teaching Language Skills, 3(2), 155-179.

Vygotsky, L. S. (1986). Thought and language. Cambridge: MIT Press.

Wigfield, A., \& Guthrie, J. T. (1997). Relations of children's motivation for reading to the amount and breadth of their reading. Journal of Educational Psychology, 89(3), 420-432.

Xiao-hui, L., Jun, W., \& Wei-hua, W. (2007). Analysis of schema theory and its influence on reading. US-China Foreign Language, 5(11), $18-21$.

Yopp, R. H., \& Yopp, H. K. (2006). Informational texts as read-aloud at school and home. Journal of Literacy Research, 38(1), 37-51.

Yu, G. (2004). Perception, practice, and progress: Significance of scaffolding and zone of proximal development for second or foreign language teachers. ELT Journal, 64 (1), 10-20. 